\title{
A Review of Wireless Power Transmission Via Solar Power Satellite
}

\author{
Makinde K, Enemuoh F. O, Lawal O. K, Umar I, Abubakar B, \\ and Mahmood M. K \\ ${ }^{1}$ department Of Electrical Engineering Federal Polytechnic Bida, Niger State \\ ${ }^{2}$ department Of Electrical Engineering Nnamdi Azikiwe University, Awka \\ Kayodemakinde2004@yahoo.com ${ }^{1}$, eneody@yahoo.com ${ }^{2}$, lawi4ril@yahoo.com ${ }^{1}$, uibida@yahoo.com ${ }^{1}$, \\ balandagisa@yahoo.com ${ }^{1}$, gimmohmk483@gmail.com ${ }^{1}$
}

\begin{abstract}
Wireless Power transmission (WPT) is a useful and convenient technology that can be employed to collect solar energy and concentrate on earth surface without the need for a wire connection called a solar power satellites (SPS). This paper provides an analysis of wireless power transfer with an assessment of its practical applicability in terms of power range and efficiency. In this paper, various technologies available so far for wireless transmission of electricity and the need for a Wireless Energy Transmission will be discussed to find its possibility in actual practices. Also, their advantages, disadvantages and economical consideration will also be presented. This paper concentrates mainly on (i) The most popular concept known as Tesla Theory, (ii) The microwave power transmission(MPT) called Solar power satellite, and (iii) The highly efficient fibre lasers for wireless power transmission. Many concepts, research papers, and patents are available on wireless transmission of electricity but the commercial technologies are yet to be materialized. This paper will also discuss the possible ways to get useful and practical results out of all researches carried out so far elsewhere. The output microwave power ranges from $50 \mathrm{~W}$ to $200 \mathrm{~W}$ at $2.45 \mathrm{GHz}$. A coaxial cable is to connect the output of the microwave source to a coax-to-waveguide adapter. This adapter is connected to a waveguide ferrite circulator which protects the microwave source from reflected power. The circulator is connected to a tuning waveguide section to match the waveguide impedance to the antenna input impedance.
\end{abstract}

Keywords: - Wireless transmission, Tesla theory, Microwave power transmission, Rectenna, Transmitting antenna

\section{INTRODUCTION}

In our present electricity generation system we waste more than half of its resources. Especially the transmission and distribution losses are the main concern of the present power technology. Much of this power is wasted during transmission from power plant generators to the consumer.

The resistance of the wire used in the electrical grid distribution system causes a loss of 26-30\% of the energy generated. This loss implies that our present system of electrical distribution is only 70-74\% efficient. We have to think of alternate state - of - art technology to transmit and distribute the electricity. Now- a- days global scenario has changed a lot and there are tremendous development in every field. If we don't keep pace with the development of new power technology we have to face a decreasing trend in the development of power sector. The transmission of power without wires may be one noble alternative for electricity transmission.

Projections of future energy needs over this new century show an increase by a factor of at least two and half, perhaps by as much as a factor of five. All of the scenarios indicate continuing use of fossil sources, nuclear, and large hydro. However, the greatest increases come from "new renewable" and all scenarios show extensive use of these sources by 2050. Indeed, the projections indicate that the amount of energy derived from new renewable by 2050 will exceed that presently provided by oil and gas combined. This would imply a major change in the world's energy infrastructure. It would be a herculean task to acquire this projected amount of energy[1].

Wireless transmission of power, also called wireless power transfer (WPT), is a means of delivering power to an end-use device without wires or contacts. One of the oldest known power transmission technologies, WPT is seeing a resurgence of interest. Scientists and engineers have known over the past century that transferring electric power does not require wires to be in physical contact. Wires typically allowed devices to receive both power and communicate with other devices. As wireless data transmission eliminates the need for wires to carry data, there is a growing need to find ways to provide power without wires making devices truly portable and mobile. With the explosive growth in wireless data applications, the market potential for wireless energy transfer technologies has seen a dramatic increase[2]. 
The Solar Power Satellite energy system is to place giant satellites, covered with vast arrays of solar cells, in geosynchronous orbit 22,300 miles above the Earth's equator. Each satellite will be illuminated by sunlight 24 hours a day for most of the year. Because of the 23" tilt of the axis, the satellites pass either above or below the Earth's shadow. It is only during the equinox period in the spring and fall that they will pass through the shadow. They will be shadowed for less than $1 \%$ of the time during the year. The solar cells will convert sunlight to electricity, which will then be changed to radio-frequency energy by a transmitting antenna on the satellite and beamed to a receiver site on Earth.

It will be reconverted to electricity by the receiving antenna, and the power would then be routed into our normal electric distribution network for use here on the Earth. As earlier mentioned, one of the major issue in power system is the losses that occurs during the transmission and distribution of electrical power. As the demand increases day by day, the power generation increases and the power loss is also increased. The efficiency of power transmission can be improved to certain level by using high strength composite over head conductors and underground cables that use high temperature super conductor. But, the transmission is still inefficient.

According to the World Resources Institute (WRI), India's electricity grid has the highest transmission and distribution losses in the world - a whopping $27 \%$. Numbers published by various Indian government agencies put that number at $30 \%, 40 \%$ and greater than $40 \%$. This is attributed to technical losses (grid's inefficiencies) and theft. Any problem can be solved by state- of -the-art technology. The above discussed problem can be solved by choosing an alternative option for power transmission which could provide much higher Efficiency, low transmission cost and avoid power theft. Microwave Power Transmission is one of the promising Technologies and may be the righteous alternative for efficient power transmission [3].

\section{SOLAR POWER SATELLITE CONCEPT}

Basic idea of SPS is to collect the solar energy in orbit and send it to ground by microwave, laser beam or some other ways. The concept of the Solar Power Satellite energy system is to place giant satellites, covered with vast arrays of solar cells, in geosynchronous orbit 22,300 miles above the Earth's equator. Each satellite will be illuminated by sunlight 24 hours a day for most of the year. Because of the 23" tilt of the Earth's axis, the satellites pass either above or below the Earth's shadow. It is only during the equinox period in the spring and fall that they will pass through the shadow. They will be shadowed for less than $1 \%$ of the time during the year. The solar cells will convert sunlight to electricity, which will then be changed to radio-frequency energy by a transmitting antenna on the satellite and beamed to a receiver site on Earth. It will be reconverted to electricity by the receiving antenna, and the power would then be routed into our normal electric distribution network for use here on the Earth. Figure 1 illustrates the concept. The great advantage of placing the solar cells in space instead of on the ground is that the energy is available 24 hours a day, and the total solar energy available to the satellite is between four and five times more than is available anywhere on Earth and 15 times more than the average location. Testing has demonstrated that wireless energy transmission to the Earth can be accomplished at very high efficiencies. Tests have also shown that the energy density in the radio-frequency beam can be limited to safe levels for all life forms. The concept is simple; the technology exists [4].

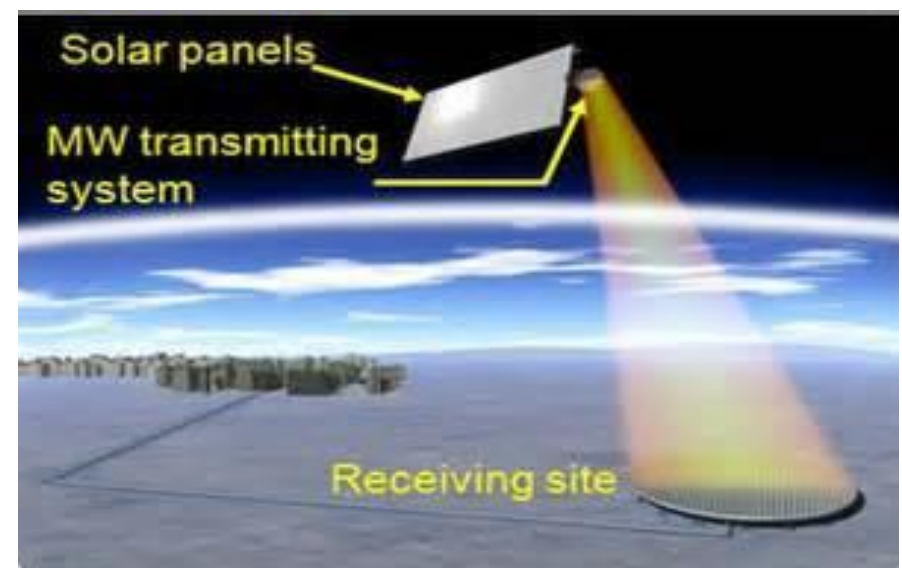

Figure 1 Components of Solar Power Satellites \& Basic Conversion Process [7].

III. WIRELESS POWER TRANSMISSION

In 1893, Nikola Tesla demonstrated the illumination of vacuum bulbs without using wires for power transmission at the World Columbian Exposition in Chicago. William C. Brown, the pioneer in wireless power 
transmission technology, had designed, developed a unit and demonstrated to show how power can be transferred through free space by microwaves. In

1961, Brown published the first paper proposing microwave energy for power transmission, and in 1964 he demonstrated a microwave-powered model helicopter that received all the power needed for flight from a microwave beam at $2.45 \mathrm{GHz}$ from the range of $2.4 \mathrm{GHz}-2.5 \mathrm{GHz}$ frequency band which is reserved for Industrial, Scientific, and Medical (ISM) applications. Typical WPT is a point-to-point power transmission. For the WPT, we had better concentrate power to receiver. It was proved that the power transmission efficiency can approach close to $100 \%$ [5]. See figure 2 for a typical reference system.

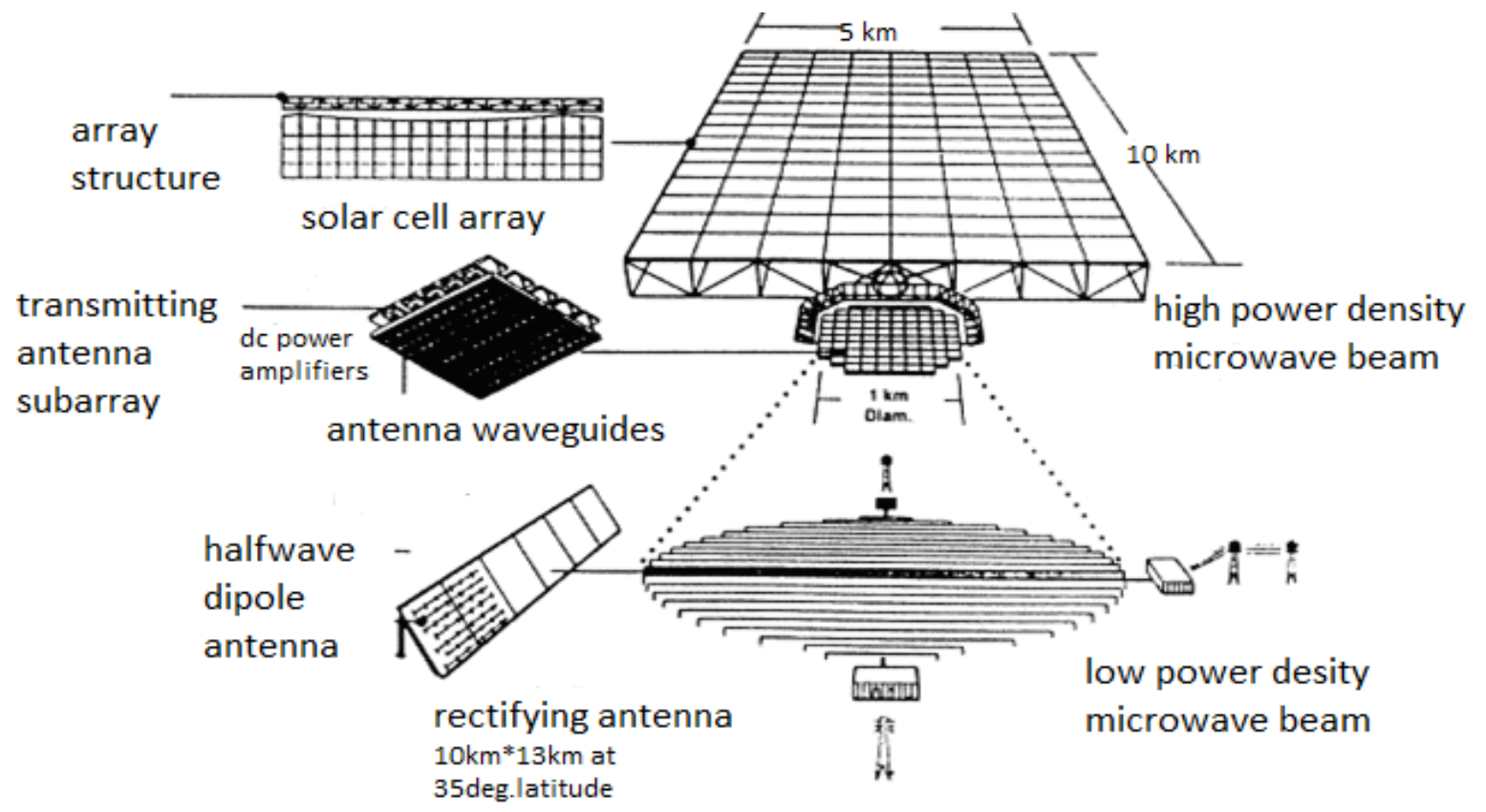

(A Fresh Look at Space Solar Power: New Architectures, Concepts and Technologies" by Mankins J., 1997, National Aeronautics and Space Administration).

Figure 2. Depicts a reference system

The main components of Wireless Power Transmission are Microwave Generator, Transmitting antenna and Receiving antenna (Rectenna). These essential components are further described in detail (Figure 1)

1) Microwave Generator: The Microwave generator takes the DC power generated by the solar cells and converts it to radiated RF output. It consists of a DC-RF conversion oscillator, which is typically low-power and followed by a gain stage and finally a power amplifier (PA).Typically the microwave generating devices are classified as microwave tubes (e.g klystron, magnetron, TWT etc) or semiconductor MW devices.

2) Transmitting Antenna: The slotted wave guide antenna, microstrip patch antenna, and parabolic dish antenna are the most popular type of transmitting antenna. The slotted waveguide antenna is ideal for power transmission because of its high aperture efficiency (> 95\%) and high power handling capability[3].

We need higher efficient generator/amplifier for the MPT system than that for the wireless communication system. For highly efficient beam collection on rectenna array, we need higher stabilized and accurate phase and amplitude of microwave when we use phased array system for the MPT.

3) Rectenna: The concept and the name 'rectenna' was conceived by W.C. Brown of Raytheon Company in the early of 1960s . A Rectenna is a Rectifying antenna, a special type of antenna that is used to directly convert microwave energy into DC electricity. Its elements are usually arranged in a multi element phased array with a mesh pattern reflector element to make it directional. Rectennas are being developed as the receiving antennas in proposed microwave power transmission schemes, which transmit electric power to distant locations using microwaves.

Rectennas are used in RFID tags; the energy to power the computer chip in the tag is received from the querying radio signal by a small rectenna. One possible future application is a receiving antenna for solar Power satellites. A simple rectenna element consists of a dipole antenna with a Schottky diode placed across the dipole elements. The diode rectifies the AC current induced in the antenna by the microwaves, to produce DC power. Schottky diodes are used because they have the lowest voltage drop and highest speed and therefore waste the least amount of power due to conduction and switching. Large rectennas consist of an array of many such dipole 
elements. Rectennas are highly efficient at converting microwave energy to electricity. In laboratory environments, efficiencies of over $85 \%$ have been observed [5].

\section{ADVANTAGES, DISADVANTAGES, AND BIOLOGICAL} IMPACTS OF WPT

\subsection{Advantages}

Wireless Power Transmission system would completely eliminates the existing high-tension power transmission line cables, towers and sub stations between the generating station and consumers and facilitates the interconnection of electrical generation plants on a global scale. It has more freedom of choice of both receiver and transmitters. Even mobile transmitters and receivers can be chosen for the WPT system. The cost of transmission and distribution becomes less and the cost of electrical energy for the consumer also would be reduced. The power could be transmitted to the places where the wired transmission is not possible. Loss of transmission is negligible in the Wireless Power Transmission; therefore, the efficiency of this method is very much higher than the wired transmission. Power is available at the rectenna as long as the WPT is operating. The power failure due to short circuit and fault on cables would never exist in the transmission and power theft would be not possible at all.

\subsection{Disadvantages}

The Capital Cost for practical implementation of WPT seems to be very high and the other disadvantage of the concept is interference of microwave with present communication systems.

\subsection{Biological Impacts}

Common beliefs fear the effect of microwave radiation. But the studies in this domain repeatedly proves that the microwave radiation level would never be higher than those received while opening the microwave oven door, meaning it is slightly higher than the emissions created by cellular telephones. Cellular telephones operate with power densities at or below the ANSI/IEEE exposure standards. Thus, public exposure to WPT fields would also be below existing safety guidelines [6].

\section{CONCLUSION}

The concept of Microwave Power transmission (MPT) and Wireless Power Transmission system is presented. The technological developments in Wireless Power Transmission (WPT), the advantages, disadvantages, biological impacts and applications of WPT are also discussed. This concept offers greater possibilities for transmitting power with negligible losses and ease of transmission than any invention or discovery heretofore made. Dr. Neville of NASA states "You don't need cables, pipes, or copper wires to receive power. We can send it to you like a cell phone call - where you want it, when you want it, in real time". We can expect with certitude that in next few years' wonders will be wrought by its applications if all the conditions are favourable.

\section{REFERENCES}

[1] www. Seminalsonly.com (2006). Surge current protection using superconductor. Accessed (6/9/13)

[2] Electric Power Research Institute (2009). Program on Technology Innovation: Impact of Wireless Power Transfer Technology: Initial Market Assessment of Evolving Technologies. EPRI, Palo Alto, CA: 2009. 1020562.

[3] Muthupriya, M. and Vinothini, S. (2013). Wireless Power Transmission Via Solar Power Satellite International Journal of Scientific and Engineering Research, Vol. 1(5), ISSN 2229-5518.

[4] Ralph H. N (1996). Wireless Power Transmission. Solar Space Industries The Key to Solar Power Satellites: IEEE AES Systems Magazine, pp 33.

[5] Akhil, N. (2012). Use of Geosynchronous Satellites for Production and Wireless Transfer of Solar Power. Available online at: http://seekdl.org/nm.php .pp81-84. Accessed (11/09/13).

[6] Mohammed S. S., Ramasamy K., and Shanmuganantham T. (2010). Wireless Power Transmission - A Next Generation Power Transmission System: International Journal of Computer Applications (0975 8887) Vol. (1)13. Available online at: http://scholarlyoa.files.wordpress.com/2013/03/wireless-powertransmission.pdf. Accessed (11/10/13).

Divya, V. and Ritesh, D. (2013). Wireless Powering Of Solar Power Satellite : International Journal of Scientific and Research Publications, Vol. 3(7), ISSN 2250-3153. Available online at: http:// www.ijsrp.org. Accessed $(11 / 10 / 13)$. 